\title{
Reflection of Comenius'Didactic Principles in ESP instruction
}

\author{
Miloslava Cerna Petra Poulova \\ University of Hradec Králové, Faculty of Informatics and Management
}

\begin{abstract}
The core of the paper represents didactic issue revealing eternal principles which might be considered universal going like a red thread through the process of education and fitting education, as well, as described in this contribution, regardless students' specialization, the level of knowledge of their field of study and individual learning styles. The main goal is to illustrate functionality and validity of particular principles which are shown in the eLearning environment of supportive e-courses from the field of education accompanying face to face classes. Description of the learning/teaching process is attended by demonstration of basic principles which were stated by Comenius already in the 17 th century but which are incredibly eternal, vivid and efficient up to now and that is why these principles form an inseparable part of current didactic principles not only in the engineering education.
\end{abstract}

Keywords: eLearning, ICT, education, didactic principles, learning management system

\section{Introduction}

The process of education is ceaselessly being innovated by the achievements of new technologies. Development and implementation of new technologies is accompanied by technical discussion and research on both field of students' study and the process of education itself. Great potential and great expectations of social software applications together with various kinds of multimedia are being discussed by teachers and researchers. Benefits of Utilization of learning management systems (LMS), social nets, and selected internet sources are compared [1].There is an infinite series of innovations in educational technology which are perceived as opportunities to revolutionize the teaching/learning process. The views on implementation of new technologies into the process of education span from purely optimistic to rather skeptical even sarcastic ones [2], [3]. New educational theories are born and old are updated; we are witnessing new taxonomies, new approaches to learning [4], new categorizations of learning styles, etc. [5].

Beside all changes reflected in current state of the process of education there are always principles perceived as a kind of generality.

Inhere presented article deals with teaching/learning process supported by the current information and communication technologies, but primarily it focuses on highlighting basic principles stated by Comenius already in the 17 th century but which are incredibly eternal after so many centuries, vivid and efficient up to now, [6], [7].

\section{Comenius' Ideas}

Johann Amos Comenius is connected with the outstanding reform of the 
educational system in the dark 17th century. He outlined and elaborated a comprehensive system of education of the individual [6], believed in encyclopedic universal system of human knowledge, in divine order of things. Pansophism in pedagogical philosophy is conclusively associated with this philosopher, [7]. His pansophic ideas are still alive and found their place in entirely 'modern' area of evaluation computerized instruction and tests [11]. Didactica Magna [12] belongs to his most famous works showing the way to effective teaching and learning. His thoughts and works brought revolutionary changes into education, his principles or theorems even now sound modern, natural and form fundamentals of didactics disregarding which philosophical paradigm is currently trendy. His Janua Linguarum Reserata [10] is nearly a 400-year-old little language textbook written for teaching Latin 'in a natural way'. This textbook might be considered as a kind of concise encyclopedia or dictionary containing list of cognizable things in Latin and Czech version.

Comenius didactic principles require e.g. purposefulness of learning; systematic and logical approach; learner's activity; clear explanations; learner's awareness of all activities relating to learning; forming long-lasting knowledge; applying adequate methods, forms, examples etc. so that the learner could understand the learning content; awaken emotionality within the learning process; apply unified approval and reach the consensus of the family and educational institutions; and others.

Despite it might seem unrealistic all his principles can be applied within the latest educational trends, including the ICTsupported process of instruction.

\section{Examples of Comenius' Principle Applied in E-Courses}

There are more than 220 e-courses supporting the process of instruction at the Faculty of Informatics and Management, University of Hradec Kralove, including the English for specific purposes where the blended learning approach is applied.

Each lesson begins with warm-up activities motivating to the new topic or revising previous one. The outline and goals are a must, clear purpose of studying is a motivating factor and corresponds to the Principles of purposefulness and activity.

Each topic is learned at various language competence levels, which relates to the Principle of steady and systematic approach and Principle of durability.

Development of communication skills is of key importance; it occupies most of the teaching/learning space, and reflects the Principle of learner's activity.

The other part of the ESP teaching/learning concept is devoted to ecourses. Six e-courses supporting ESP teaching and learning are designed in the LMS Blackboard. Structure of each ecourse and lesson scheme follow the same pattern, thus covering the Principle of systematic approach. The Entry page contains learning objectives; Study material of different types and from various sources and key vocabulary are always placed at the top of the page; and at least two quizzes or assignments are provided in each lesson test learner's knowledge (figure 1).

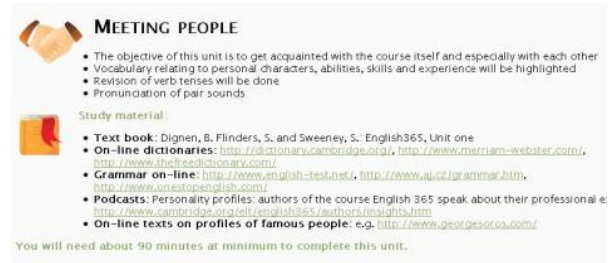

Figure1. Entry page into the unit with objectives, links to study materials and time needed to complete the unit 
Tasks represent new stage in the learning process. That is why there are various kinds of tasks to fit individual learner's preferences and learning styles. Two main principles are applied there: the Principle of Active approach and the Principle of Awareness showing that student really understands the issue and knows how to use the knowledge creatively (figure 2). This is a meaningful part which represents the desired outcome of the learning process. Stating goals and desired outcomes is based on the Bloom taxonomy.

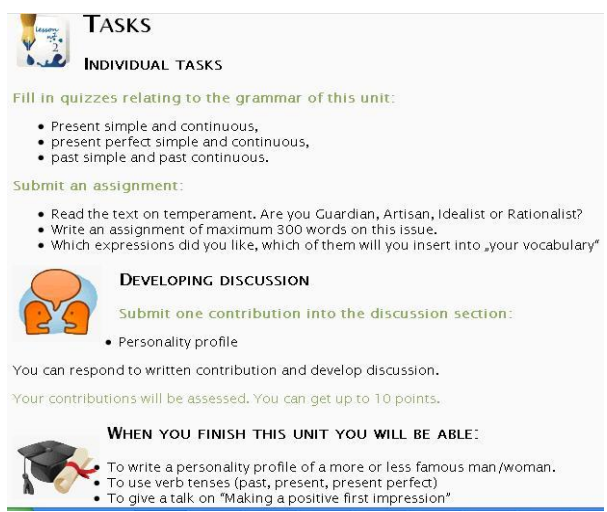

Figure 2. Tasks and activities enabling mastering the goal of the unit together with expected outcomes

Each electronic study material is accompanied by images or icons bearing constantly the same meaning to ensure unified design and clear navigation through the e-course (the Principle of Systematic approach is applied there (figure 2).

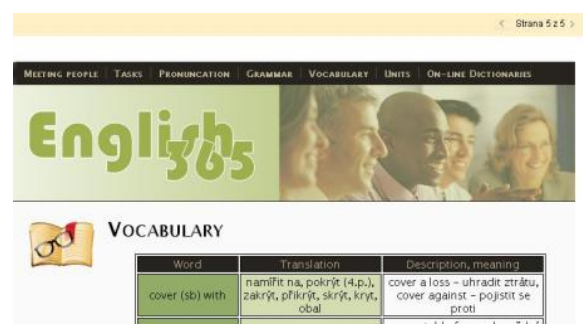

Figure 3. Navigation bar and extract from vocabulary page
Navigation through the course is provided by the main menu which may me tailored to the needs of a subject or learner (figure 3 ).

The course was designed as online course; students can work in the offline mode when they work out their assignments. To meet the demands of students a set of materials from the learning module was prepared so that the students could download it from the ecourse.

All e-courses are highly adaptive. Easy navigation system and clear transparent design make provided learning material easy to follow and "swallow", as required by the Principle of Clearness and Principle of Adequacy.

Prompt feedback, challenging tasks, supplementary material for study enthusiasts are proven motivating aspects covering the Principle of Systematic Approach and Principle of Fun and Game.

Teachers find positive the possibility to have their own separate online language section and add materials that suit their group.

\section{Conclusion}

The article provides readers with a wide and deep analysis of ESP teaching/learning at FIM UHK; it reveals eternal human value of Comenius' principles in the entirely technical environment.

The paper strives for display and explanation of a way how modern approaches to teaching/learning languages, which are based on information and communication technologies, might naturally mingle with a medieval approach to the process of education elaborated by Johann Amos Comenius.

Studying languages is specific with its requirements on both teachers and students, generous with its possibilities 
and uncertain with its outcomes [11]. The analysis demonstrates how educators can use the learning sciences and inhere described e-course to design more effective formal and informal learning environments.

\section{References}

[1] Černá, M., Poulová, P. Draessler, J., Software Applications in Academic Setting - Awareness and Satisfaction, Interactive collaborative learning (ICL2011) - 11th International Conference Virtual University, VU'11, 2011.

[2] Schroeder, A., Minocha, S., Schneider C. The strengths, weaknesses, opportunities and threats of using social software in higher and further education teaching and learning, Journal of Computer Assisted Learning, vol. 26, pp. 159 174, 2010.

[3] Selvyn, N. The use of computer technology in university teaching and learning: a critical perspective. Journal of Computer Assisted Learning, vol. 23, pp. 83-94, 2007.

[4] Orvig, C., Ways to Approach Language Learning, [on-line] http://www.sil.org/lingualinks/LANG UAGELEARNING/WaysToApproac hLanguageLearning/WaysToApproac hLanguageLearning.htm

[5] Šimonová, I., Learning styles in foreign language instruction. Interactive collaborative learning
(ICL2011) - 11th International Conference Virtual University, VU'11, pp. 595-601, 2011.

[6] Comenius, J. A. Comenius, selections from his works. Praha: SPN, 1964.

[7] Contributions. Contributions, Works - Human, Education, God and Amos. [on-line] http://education.stateuniversity.com/p ages/1868/Comenius-Johann-15921670.html

[8] Small, L. The Pansophism of John Amos Comenius (1592-1670) as the Foundation of Educational Technology and the Source of Constructive Standards for the Evaluation of Computerized Instruction and Tests. International Conference on Technology and Education, 1990.

[9] Comenius, J. A. The Great Didactic of John Amos Comenius: Now for the First Time, tr. and ed. Maurice W. Keatinge. New York: Russell and Russell, (1967).

[10] Janua linguarum reserata: sive, Omnium scientiarum \& linguarum seminarium ... The Gate of Languages unlocked: or, a Seed-plot of all arts and tongues; London, 1673,

[11] Poulová, P., Šimonová, I. eLearning at Czech universities in 1999 - 2010. e-Learning : proceedings of the 9th European conference. Reading : Academic publishing, pp. $512-520$, 2010. 